\title{
How not to assess Probation Performance: constructing local reconviction rates
}

\author{
Carol Hedderman, University of Leicester
}

\begin{abstract}
Much of the responsibility for securing reductions in offending and reoffending is being devolved to local statutory services. It follows that robust and timely local measures for assessing reoffending must be created. To this end, for the last three years the National Offender Management Service has produced quarterly reconviction reports for individual probation areas based on 'snapshots' (cross-sectional samples) of the supervision caseload. An independent examination of the data for the East Midlands Region reveals that the way cases have been selected and followed-up departs from the conventions employed in all previous ('Iongitudinal') reconviction studies in England and Wales. In particular, the 'cross-sectional' or snapshot approach led to the 'at risk' period varying from one offender to another; and those on longer sentences stood a much greater than usual chance of appearing in several samples over time. This, together with other problems associated with not following a conventional longitudinal approach, leads to the conclusion that it would be unwise to use the quarterly figures produced thus far to draw conclusions about probation areas' performance.
\end{abstract}

\section{Acknowledgements}

The author would like to thank Heather Munro, Chief Executive of the Leicester and Rutland Probation Trust, for initially commissioning this study and the other Chief Officers of the East Midland Region who also generously supported the project. Their patience and interest were much appreciated. Thanks are also due to Natasha Garnham (National Offender Management Service) and Simon Marshall (Deputy Regional Offender Manager for the East Midlands) for facilitating access to the data. I am especially grateful to Sarah Deacon of RDS NOMS for coming to the rescue and providing the useable dataset and a careful and clear guide to its construction. Finally, I would like to thank David Elliott for his advice on the analysis and being a willing sounding board for my thinking about the results.

\section{Biographical note}

Carol Hedderman is Professor of Criminology at the University of Leicester and a member of the Griffins Society Council. She was formerly Assistant Director of the Home Office Research and Statistics Directorate (2002-2004) where she had lead responsibility for statistics and research concerning sentencing and the management and impact of the Prison and Probation Services. 


\section{How not to assess Probation Performance: constructing local reconviction rates}

The government created the National Offender Management Service (NOMS) in the light of the first Carter Report's recommendation that the probation and prison services should be brought together to secure the 'end-to-end' management of offenders (Carter, 2003). The aim of that management process is to reduce reoffending. Responsibility for delivering this objective has been devolved to ten regional offices in England and Wales which are each overseen by a Regional Offender Manager (ROM) or Director of Offender Management (DOM). The ROM or DOM is expected to achieve reductions in reoffending by overseeing the coordination of prisons, probation areas and other statutory and voluntary sector agencies (Home Office, 2004).

If local services and regions are to be held to account for securing reductions in reoffending, it follows that the effectiveness with which they do so should be measured at a local and regional level. With this in mind, the research arm of NOMS has undertaken several annual rounds of a reconviction analysis designed to generate quarterly regional reconviction rates. The results are not yet in the public arena but they have been disseminated to regions for consideration and comment. Part of the response from Probation Chiefs in the East Midlands Region was to commission the current study, so that they could consider the value of these results as a measure of local performance.

When this regional project was initially conceived, it was assumed that quarterly samples would be drawn using standard reconviction study sampling techniques, so the original plan was to supplement the centrally conducted analysis, for example, by comparing reconviction rates according to the type, conditions and length of community orders. When it became clear cross-sectional sampling had taken place, it was agreed that the primary focus should be on assessing the value of reconviction rates based on crosssectional data. This was to be followed by an examination of variation in probation area caseloads within the East Midlands Region in terms of factors known to affect reconviction such as age, sex, type of current offence, type of 
supervision and criminal history. This article discusses the results of those analyses.

\section{Using reconviction rates to assess the effectiveness of different sentences}

Before considering the specific results generated by the current study, it is worth considering the general value of using reconviction rates to assess effectiveness.

It is tempting to assume that one can assess the extent to which any given sentence, or intervention within a sentence, has reduced reoffending by measuring offending before and after a sentence has been imposed (Hedderman, 2007). But, as Lloyd, et al., (1994) explain in their seminal study of reconviction, that is an impractical plan for a number of reasons. First, it assumes that nothing else has influenced the change. Second, it assumes that an offender would otherwise have maintained a steady rate of offending. Third, it is clearly not reasonable to compare the impact of a two year period in custody with two years on a community order from the day both sentences were imposed, as the periods 'at risk' of further offending differ. ${ }^{1}$ Fourth, we cannot measure reoffending directly, but use proxies such as rearrest and reconviction or self-reported offending which all distort the underlying picture in some way.

Mair et al. (1997) even question whether it is appropriate to assess the impact of a sentence (or intervention within a sentence) in terms of aims it was not imposed to achieve; or to measure its success in relation to only one aim, when it was imposed to achieve several. Also, in practice, researchers can only speculate on precisely how a reduction in reconviction was achieved even when an outcome study is accompanied by a well-conducted process evaluation. It is simply assumed that penalties which are intended to be

\footnotetext{
${ }^{1}$ Even taking acts against other inmates into consideration would not solve this problem as the prison environment clearly limits an inmate's ability to commit specific types of offence (child abuse and car theft being among the most obvious).
} 
rehabilitative have primarily worked in this way. Similarly, sentences which are intended to deter are assumed to have had a primarily deterrent effect.

The lack of agreed and objective measures of incapacitation or general deterrence (Moxon, 1998), also tends to limit most discussions of sentencing effectiveness. For example, while the Carter Review (2003) concluded that the increased use of custody probably made a modest contribution to crime reduction during the 1990s, this conclusion relied on (unpublished) statistical modelling. It was not a directly observed relationship (Hedderman, 2006).

Despite the considerable conceptual differences in how incapacitation and deterrence are expected to operate, reviews tend to conclude that their effects are not distinguishable from one another (Nagin, 1998; von Hirsch et al., 1999; Carter, 2003; Bottoms, 2004). Another common conclusion is that while increasing the use of imprisonment might lead to some additional incapacitative effect or marginal deterrence, increasing the risk of being caught is a more effective way of securing crime reduction (von Hirsch et al., 1999). This inability to distinguish one effect from another leads Friendship et al. (2004) to conclude that reconviction's value as an outcome measure lies in the fact that, quite simply, it is often the only one available.

\section{Conventional approaches to conducting reconviction studies}

There are no universal standards for conducting reconviction studies but there are common conventions which have developed in England and Wales because these secure the most reliable and robust results. Perhaps the most obvious example of this is that using reconvictions ${ }^{2}$ to measure reoffending is generally preferred to rearrest because the latter may be affected by decisions other than proof of an offender's guilt (Lloyd et al., 1994). For example, when there is no clear single suspect, the police may arrest several potential candidates, some (or all) of whom may not be prosecuted or convicted. Similarly, the decision to re-imprison an offender may not be a

\footnotetext{
${ }^{2} \mathrm{~A}$ reconviction involves a further finding of guilt or an admission of guilt in court.
} 
response to reoffending but the result of a failure to attend probation appointments or a breach of licence conditions, so it is a less reliable measure of reoffending than reconviction. In the same way, while the use of two year follow-up periods has become the norm that is because, if an offender is reconvicted at all, this is most likely to occur - and result in a conviction - within such a timeframe. In fact, most reoffending happens, if it occurs at all, within the first year of a community sentence being imposed or following release from prison (Kershaw and Renshaw 1997a; 1997b). While reconviction periods which are shorter than two years give more timely feedback, they are known to undercount serious offences because these take longer to come to court and to be finalised. Even two years is not generally considered long enough for sex offender reconviction studies because such offences are harder to uncover (Beech et al., 2001).

Another important convention is that reconviction studies adopt a longitudinal rather than the cross-sectional design more commonly employed in social research. The critical characteristic of a longitudinal design is that all of those in the sample and comparison groups are at the same stage of life or at the same stage of an intervention. Probably the most famous criminological longitudinal studies are the Cambridge (e.g. Farrington et al, 2006) and Pittsburgh (e.g. Loeber and Stouthamer-Loeber, 1998) birth cohort studies in which children born in the same year and the same location (South London and Pittsburgh, respectively) were followed up from birth in order to understand how and why individuals begin to offend and what personal, social and experiential factors are associated with persistence and desistance. While it would have been both quicker and cheaper to take a cross-sectional approach in which different age groups at each site are sampled simultaneously, this would yield less reliable results. As the Economic and Social Research Council's United Kingdom Longitudinal Research Centre (ULSC, 2008) explains on its website: a longitudinal approach is considered preferable when seeking to identify the causes of change and causal processes; when there is a need to exclude the potential effects of age and time; and 'when establishing the effect of a 'treatment' by following an 
experimental or quasi-experimental design or comparing periods before and after the introduction of public policy'.

Adopting a longitudinal design for reconviction studies ensures that all those being compared are at the same point in a sentence and begin with the same potential follow-up period. As noted above, given that most reoffending occurs as supervision begins, it is important to ensure that this period is captured in full for all cases in the sample. Otherwise the comparison is not taking place on a like-for-like basis. A longitudinal approach also ensures that the sequencing in which effects occur is unambiguous (Blumstein et al.,1988).

Choosing a longitudinal approach also ensures that the sample is robust by ensuring that those sentenced or released on a given date will stand an equal chance of being included regardless of sentence length. In a cross-sectional sample, the chances of being included increase with time on supervision. This also means that when further samples are being drawn, there is a risk that these will be non-independent as those on longer sentences may be chosen again. Adopting a longitudinal approach reduces the chances of this occurring as the same offender will only be included in subsequent samples if they have begun a new community sentence or been re-released. .

For these reasons most reconviction studies undertaken by government analysts and independent researchers in this country and elsewhere adopt a 'longitudinal' approach (see, for example, Home Office, 1993; Kershaw and Renshaw, 1997a; Kershaw and Renshaw, 1997b; Oldfield, 1997; Killias et al., 2000; Spicer and Glicksman, 2004; Cuppleditch and Evans, 2005; Cunliffe and Shepherd, 2007). This involves following samples of offenders on community orders forward from date of sentence and prisoners forward from date of release from prison. Under this approach, the definition of a previous conviction is simple and intuitive as it covers any convictions which relate to offences committed before the previous sentence date; and reconvictions are those relating to offences which occurred after the date of sentence or release. It is sometimes necessary to exclude 'pseudo-reconvictions' which are convictions which occur during the follow up period, but which result from 
offences committed prior to the sentence of interest. These are excluded from reconviction studies because they are not a measure of the current sentence's effectiveness.

When comparing the reconviction rates associated with different types of sentence, across areas or over time, it is important to allow for differences in factors known to associated with further offending (Kershaw and Renshaw, 1997b; Cunliffe and Shepherd, 2007). The most commonly controlled factors are age, sex, age at first offence, nature and extent of previous offending and experience of previous sentences. This is mainly because these characteristics are known to be highly correlated with reconviction.

Adopting the standard two year follow-up period means that any offence committed within twenty-four months will be counted as a reconviction, whereas one committed after twenty-four months have passed will not. This is true regardless of whether the offender has moved from a pattern of rape and burglary to one of low-value shoplifting or escalated from taking and driving away to armed robbery. It may also miss 'some short-term impact which 'decays' into no difference in reconviction over two years' (Merrington and Stanley, 2004:18). Unsurprisingly, numerous commentators (e.g. Lloyd et al, 1994; Merrington and Stanley, 2004, 2007) have concluded that while the value of the single headline figure approach lies in its simplicity, this comes at a price. For these reasons, a number of recent studies include supplementary or alternative measures which take account of the nature of subsequent offending (e.g. Friendship et al., 2003); the time taken to reoffend (e.g. Sarno et al., 2001), the extent to which changes in offending are sustained (e.g. Cann et al., 2003); and the relationship between known reconvictions and self-report (e.g. Farrall, 2005). These additional measures are likely to assume greater importance as our understanding of reducing reoffending as a process of desistance ${ }^{3}$ increases.

\footnotetext{
${ }^{3}$ See, for example, Farrall (2002) and McNeill (2006),
} 


\section{The NOMS cross-sectional approach to generating local reconviction rates}

To generate the data on which reconviction rates are calculated, probation areas are required to send data on cases on their caseloads on four quarterly census dates. These returns are then matched to Police National Computer (PNC) information on known convictions or cautions relating to offences committed within three months and recorded on the PNC within six months.

The protocols used to decide whether local or central information should be considered accurate when the local and central source conflicted were not released nor was any information provided on the extent to which such conflicts arose. However, judging from the crude categories used to describe ethnicity and the fact that the nature of the principal offence was missing in between $11 \%$ and $21 \%$ of cases (see below), it seems likely that preference was given to PNC data and that local information was over-written. Alternative approaches might have included taking whichever source provided the fullest record or creating rules to over-write or amalgamate data based on specific criteria. For example, if one source showed an offence as $A B H$ and another as $\mathrm{GBH}$, the rule might either call for the more serious of two violent offences to be accepted or both could be combined as a principal offence of 'violence' or 'violence involving injury'.

Despite initial promises that creating local reconviction measures would be an iterative and transparent process, it took eighteen months for an analysable dataset to be received. This comprised 49,720 records drawn from the East Midlands Region probation areas (Derbyshire, Leicestershire, Lincolnshire, Northamptonshire and Nottinghamshire) on four dates in 2006 (31 Mar, 30 June, 30 September and 31 December). Approximately $10 \%$ of the offenders being supervised by each area at each sample point were not matched on the Police National Computer (PNC) where the reconviction data are held. ${ }^{4}$

\footnotetext{
${ }^{4}$ The general consistency of matching over time and area means that the missing cases are unlikely to explain variation in reconviction rates.
} 
Table 1: number of cases under supervision per area and per sample

\begin{tabular}{|l|r|r|r|r|r|r|}
\hline & $\begin{array}{l}\text { Derby- } \\
\text { shire }\end{array}$ & $\begin{array}{l}\text { Leic \& } \\
\text { Rutland }\end{array}$ & Lincs & Northants & Notts & \multicolumn{1}{l}{$\begin{array}{l}\text { East } \\
\text { Midlands }\end{array}$} \\
\hline \multirow{3}{*}{$\begin{array}{l}\text { 31 March 2006 June 2006 } \\
\text { 30 Sept 2006 }\end{array}$} & 2764 & 2787 & 1451 & 1523 & 3901 & 12426 \\
\cline { 2 - 7 } & 2675 & 2844 & 1462 & 1528 & 3823 & 12357 \\
\cline { 2 - 7 } 31 Dec 2006 & 2708 & 2997 & 1526 & 1603 & 3691 & 12525 \\
\hline Total & 10847 & 11591 & 5966 & 6200 & 15116 & 49720 \\
\hline $\begin{array}{l}\text { Percentage of } \\
\text { regional } \\
\text { supervision load }\end{array}$ & $22 \%$ & $23 \%$ & $12 \%$ & $12 \%$ & $31 \%$ & $100 \%$ \\
\hline
\end{tabular}

Once the data were received it quickly became clear that initial plans to refine and add to the existing central analyses through more detailed local ones which looked at specific types of reoffending or which compared different types of sentencing were not worth pursuing. The data simply did not provide an adequate or reliable basis. ${ }^{5}$ Instead the analyses focused on assessing the impact of the decision to adopt such an unconventional approach to assessing reconviction. In fact, the NOMS decision to take a cross-sectional approach to creating local probation reconviction samples and to the analysis created at least four serious obstacles to making sense of the results. These were entirely predictable whereas the reasons for departing from the longitudinal convention, aside from improved sample sizes, are unclear. ${ }^{6}$

First, sampling those who happened to be under supervision on a given date meant that individuals in the sample had been sentenced days, weeks, months or even years before this date. The analysis presented in Table 2 is based on the first 2006 snapshot date (31 March 2006). This shows that 18\% or about 1 in 6 community orders in the region were over a year old. The figure for the full year's sample was also $18 \%$. However, some of the other quarters contained even greater variation between areas. For example, the proportion of cases which had been supervised for more than a year in

\footnotetext{
${ }^{5}$ The usual demographic characteristics (e.g. age, sex, ethnicity) of the sample as a whole are not discussed at this point because they need to be understood in the light of the methodological discussion provided.

${ }^{6}$ Of course, sample size issues can be addressed by sampling over a period rather than just one day in a longitudinal study, with the follow-up period being extended in the same way.
} 
Derbyshire (24\%) was nearly twice that for Lincolnshire $(13.5 \%)$ in the December sample.

Table 2 Time elapsed between sentence date \& 31 March 2006 by area

\begin{tabular}{|l|r|r|r|r|r|r|}
\hline & \multicolumn{1}{l|l|l|}{$\begin{array}{l}\text { Derby- } \\
\text { shire }\end{array}$} & \multicolumn{1}{l|l}{$\begin{array}{l}\text { Leic \& } \\
\text { Rutland }\end{array}$} & Lincs & Northants & Notts & $\begin{array}{l}\text { East } \\
\text { Midlands } \\
\%\end{array}$ \\
\hline $\begin{array}{l}0-6 \\
\text { months }\end{array}$ & 50.6 & 54.0 & 56.3 & 50.4 & 56.5 & 53.9 \\
\hline $\begin{array}{l}7-12 \\
\text { months }\end{array}$ & 28.2 & 29.1 & 27.4 & 30.9 & 26.2 & 28.0 \\
\hline $\begin{array}{l}13 \text { or more } \\
\text { months }\end{array}$ & 21.2 & 16.9 & 16.3 & 18.7 & 17.3 & 18.2 \\
\hline $\begin{array}{l}\text { Number of } \\
\text { community } \\
\text { sentences }\end{array}$ & 2348 & 2337 & 1242 & 1227 & 3248 & 10402 \\
\hline
\end{tabular}

Two out of every five licence cases in each snapshot had been supervised for over a year. For both community supervision and custody cases, variation between areas was highly statistically significant $(P \leq 0.0001) .{ }^{7}$ For example, the average (mean) period which had elapsed between release and the first snapshot date was 48 weeks in Leicestershire and Rutland, 51 weeks in Derbyshire, 57 weeks in Northamptonshire, 58 weeks in Lincolnshire and 70 weeks in Nottinghamshire. This means that some of those sampled were followed up from early in their 'at risk' period, while others were sampled as their likelihood of first reconviction was fading. A sizeable minority, particularly among custody cases, were sampled when their risk of first reconviction was negligible following years of supervision. The fact that individual probation areas differed in this regard to a highly significant level in all four snapshots means that the chances of their reconviction rates falling were unequal. As it would be unfair and misleading to present individual probation areas' results, Table 3 illustrates the consequences for all of those on community sentences using the March 2006 cohort. As expected reconviction rates fell as time since sentence increased.

\footnotetext{
${ }^{7} \mathrm{~A}$ result is referred to as being 'statistically significant' if the probability of it occurring by chance is less than, or equal to, 1 in $20(P \leq 0.05)$.
} 
Table 3: Three month reconviction rates according to time elapsing

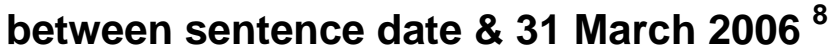

\begin{tabular}{|c|c|c|c|c|}
\hline & \begin{tabular}{|l} 
Up to 6 \\
months \\
$\%$
\end{tabular} & $\begin{array}{c}\text { months } \\
\text { \% }\end{array}$ & \begin{tabular}{|l|} 
Over 12 \\
Months
\end{tabular} & Total \\
\hline No further offending & 88.7 & 90.7 & 93.3 & 90.1 \\
\hline Proven reoffence & 11.3 & 9.3 & 6.7 & 9.9 \\
\hline Total $\mathrm{N}$ & 5603 & 2911 & 1888 & 10402 \\
\hline
\end{tabular}

Table 4 presents similar information for licence cases. This comparison is limited to dividing cases according to whether the time since release was more or less than a year because of the smaller numbers and generally longer supervision periods involved. The reconviction difference according to time on supervision was only statistically significant for two snapshots (June and December) but the trend was the same in all four periods, with those who had been on licence for less than a year being more likely to be reconvicted than those who had been out in the community for longer. ${ }^{9}$

Table 4: Three month reconviction rates according to time elapsing between release date \& 31 March $2006^{10}$

\begin{tabular}{|l|r|r|r|}
\hline & 12 months and under & Over 12 Months & Total \\
& $\%$ & $\%$ & $\%$ \\
\hline No further offending & 91.4 & 93.3 & 92.2 \\
\hline Proven reoffence & 8.6 & 6.7 & 7.8 \\
\hline Total N & 1100 & 879 & 1979 \\
\hline
\end{tabular}

Generally speaking, the more an area's caseload includes orders which have been running for a long time, the lower its reconviction rates are likely to be. The importance of this lies in the intention to use area reconviction rates as performance indicators. In this context, the simplest option open to an area

\footnotetext{
${ }^{8}$ Given that the reconviction statistics for 2005 (Ministry of Justice, 2008) show that $38 \%$ of those on community sentences were reconvicted within one year, a reconviction rate of $10 \%$ in three months may seem low. However, after allowing for the effects of pseudoreconvictions, changes in probation population and other differences in which community penalties were included in the comparison, this is remarkably consistent with Kershaw and Renshaw (1997b) finding that $15 \%$ of those on probation in 1993 were reconvicted within three months, $46 \%$ within one year and $57 \%$ after two years.

${ }^{9}$ Fisher's exact test $(1$ sided) was used to test for significance in licence cases to allow for small numbers.

${ }^{10}$ A three month reconviction rate of $9 \%$ is consistent with Kershaw and Renshaw's (1997a) finding that $8 \%$ of those released from prison in 1993 were reconvicted within three months, $37 \%$ within one year and $53 \%$ after two years. Reconviction statistics for 2005 (Ministry of Justice, 2008) show that $49 \%$ of adult offenders on released from custody were reconvicted within one year. See Hedderman (2008) for a discussion of why probation one year reconviction rates may have remained relatively stable over time while prison reconviction rates have grown so substantially.
} 
seeking to reduce its reconviction rates would be to encourage local sentencers to impose longer orders. This is a perverse incentive because this would add to the costs of criminal justice without any beneficial effect on public safety. Both the community sentence and licence reconviction results support the conclusion that local reconviction rates would be more meaningful, and less easy to manipulate, if they were based on cases commencing supervision rather than snapshots drawn from caseloads.

It is interesting to note that since these results were disclosed to NOMS an (unpublished) set of revised results covering March 2006 to June 2007 have been released to areas which takes account of time since sentence or release. This may ameliorate the problem but it will only solve it if it is the passage of time which reduces reconviction, rather than the changes to offenders' attitudes and behaviour during that time, which affect likelihood of reconviction. In other words, this statistical correction may suppress the impact of not comparing like-with like, but it does not address the basic issue which has led to other reconviction studies adopting a longitudinal approach.

Allowing for time since sentence or release also will not solve a second related problem created by adopting a cross-sectional approach which is that it compromises the validity of any comparison between actual reconviction rates and standard predictors of reconviction which calculate risk from the date of sentence. In other words, as Blumstein et al. (1988) point out, it creates ambiguity in the time line, as age and experiences may have affected the risk of reconviction between the date for which it was calculated and the date to which it was applied.

A third - predictable - problem created by the cross-sectional snapshot approach concerns the extent to which any single individual appear in the four snapshots. Those on very short orders (any under three months) did not stand an equal chance of being sampled in any quarter as they were excluded if they began and completed supervision after one snapshot ended and another began. It follows that certain types of orders are more likely than others to be missed (e.g. those involving short periods of community 
punishment). On the other hand those on longer sentences were more likely to be sampled in more than one quarter. In practice, this meant that the overall sample of 49,720 cases for the East Midlands Region in 2006 related to only 21,554 individuals of whom more than two thirds (68\%) appeared in more than one sample. Table 5 shows that three quarters $(76 \%)$ of those who appeared in one snapshot appeared in at least one other. The fact that the different samples often contained the same people dramatically limits the extent to which changes in reconviction over time can be expected. Once again area differences were statistically significant which means that the impact this had on reconviction will vary between them.

Table 5: the extent of overlap between offenders in each snapshot

\begin{tabular}{|c|c|c|c|c|c|c|}
\hline & 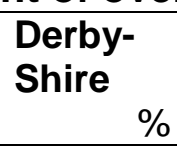 & $\begin{array}{l}\text { Leic \& } \\
\text { Rutland } \\
\%\end{array}$ & $\begin{array}{l}\text { Lincs } \\
\% \\
\end{array}$ & $\begin{array}{r}\text { Northants } \\
\% \\
\end{array}$ & $\begin{array}{r}\text { Notts } \\
\% \\
\%\end{array}$ & $\begin{array}{l}\text { East } \\
\text { Midlands } \\
\% \\
\end{array}$ \\
\hline One snapshot & 13.6 & 13.0 & 14.5 & 14.1 & 14.8 & 14.0 \\
\hline Two snapshots & 22.8 & 22.4 & 23.2 & 22.6 & 24.6 & 23.3 \\
\hline Three snanshots & 22.5 & 25.0 & 26.9 & 23.2 & 24.7 & 24.4 \\
\hline & 41.2 & 39.6 & 35.4 & 40.1 & 35.9 & 38.4 \\
\hline Total Percentage & 100.0 & 100.0 & 100.0 & 100.0 & 100.0 & 100.0 \\
\hline Total N & 10847 & 11591 & 5966 & 6200 & 15116 & 49720 \\
\hline
\end{tabular}

The fourth major problem created by NOMS' decision to take a crosssectional approach is that it has led to questionable decisions being made about what to count as a previous conviction and what to count as a reconviction. In line with standard reconviction study protocols any incident which occurred in the three months following a snapshot date which resulted in a caution or conviction within 6 months of the snapshot date is counted as a reconviction; and any offence which occurred before the snapshot date was treated as a previous conviction. However, because the snapshot date was not the sentence or release date this means that any offence which occurred before the snapshot date but which had occurred during the same period of supervision is counted as a previous conviction. Put simply, this convoluted approach leads to the measure of previous convictions over-counting offending and the measure of reconviction undercounting offending. Following 
the logic of this approach means that an offender who appears in all four snapshots who offended during the first three but not in the fourth will appear as a 'success' in the final snapshot as the offender's previous failures during the same order will all be treated as previous convictions by that point. Indeed the offender may well be seen to be outperforming his or her expected reconviction rate if the three previous failures form part of the risk of reconviction calculation. Unfortunately, too little information is provided in area reports to know quite how the predictor is calculated.

\section{Other factors which may affect an area's reconviction rates}

Given the limited caseload turnover between samples, it is unsurprising that the profile of each area was stable over time on all demographic, offending and sentencing factors. Areas were similar to each other in terms of the percentage of women (13\%) on the caseload; average age (mean= 31 years $/$ median $=29$ years $)$.

The ethnicity of 86 per cent of the regional sample was classified as 'White European'11, but underlying this were large differences between areas. For example, less than two per cent of Lincolnshire's probation caseload was classified as Black or Minority Ethnic (BME) and no BME group was significantly more common than another. In contrast, one in five of those being supervised in Leicestershire and Rutland were from a BME group and, while. 'Asians' (12\%) comprised the largest single BME group in Leicestershire and Rutland, the 'Afro-Caribbean' group was also comparatively large (8\%). Nottinghamshire had a similar proportion of AfroCaribbean offenders $(9 \%)$, but supervised a much smaller percentage of Asian offenders (3\%). The only significant change in an area's ethnic profile over time occurred in Nottinghamshire and was explained by an increase in the proportion of cases where ethnicity was unknown (3.4\% to $7.4 \%)$.

\footnotetext{
${ }^{11}$ The crude (even offensive) ethnic codes included in the data indicate that 'ethnic appearance' as recorded by the police on the PNC was used in preference to local probation information.
} 
The caseloads of areas also varied significantly in the extent to which they comprised those on community sentences or released from prison, with Derbyshire having the lowest proportion of licence cases and Northamptonshire having the highest (see Table 6). This may contribute to an explanation of differences between area reconviction rates.

Table 6: variations in supervision by area (all time periods)

\begin{tabular}{|l|r|r|r|r|r|r|}
\hline & $\begin{array}{l}\text { Lerby- } \\
\text { Shire } \\
\text { \% }\end{array}$ & $\begin{array}{l}\text { Leic \& } \\
\text { Rutland } \\
\%\end{array}$ & \multicolumn{1}{l|}{ Lincs } & Northants & Notts & $\begin{array}{l}\text { East } \\
\text { Midlands } \\
\%\end{array}$ \\
\hline $\begin{array}{l}\text { Community } \\
\text { Supervision }\end{array}$ & 85.4 & 83.9 & 85.1 & 81.3 & 82.9 & 83.7 \\
\hline Licence & 14.3 & 15.8 & 14.6 & 18.3 & 16.8 & 15.9 \\
\hline $\begin{array}{l}\text { Mixed or } \\
\text { missing }\end{array}$ & .3 & .3 & .2 & .3 & .4 & .3 \\
\hline Total N & 10847 & 11591 & 5966 & 6200 & 15116 & 49720 \\
\hline
\end{tabular}

Although all the areas varied in their use of different community sentences, Derbyshire's and Northamptonshire's supervision cases also seemed to differ from the other three areas in that, proportionately, they supervised more Community Rehabilitation Orders (CROs), fewer Community Punishment and Rehabilitation Orders (CPROS) and fewer sentences imposed under the provisions of the Criminal Justice Act 2003 sentences than the other three areas. There are several potential explanations for this including: errors in the data; that Derbyshire and Northamptonshire were supervising a less serious caseload; and/or that they were supervising offenders on longer orders. The fact that the disparity in the use of these different community sentences grew over time supports the idea that sentence length is a factor.

Just under a quarter (23\%) of the cases under supervision in the East Midlands region involved violence. The next most common offences were theft and handling (10\%), drink driving (8\%), other motoring offences $(8 \%)$ drugs supply and possession (7\%) and public order (6\%). Other offences all comprised less than $5 \%$ each of area caseloads. Underlying these averages were important area differences, particularly in relation to violence, burglary, 
sexual offences, drink driving and theft (see Table 7). Of course, the nature of offending is known to be related to likelihood of reoffending, so any meaningful comparison between areas' reconviction rates would need to allow for these differences. Further analysis showed that offence seriousness may have played a part in the different supervision pattern discernible in Northamptonshire. This area supervised a much higher proportion of drink drivers than average. However, Derbyshire's cases which, like Northamptonshire, involved more CROs than average, involved a fairly typical distribution of offences.

Table 7: The nature of the principal offence leading to current supervision by area (all time periods)

\begin{tabular}{|l|r|r|r|r|r|r|}
\hline & $\begin{array}{l}\text { Derby } \\
\text { shire }\end{array}$ & $\begin{array}{l}\text { Leic } \\
\text { Rutland }\end{array}$ & Lincolns & Northants & Notts & $\begin{array}{l}\text { East } \\
\text { Midlands }\end{array}$ \\
\hline Violence & 24.8 & 24.1 & 21.8 & 21.4 & 22.1 & 23.0 \\
\hline Burglary & 3.1 & 2.9 & 4.0 & 3.5 & 5.5 & 3.9 \\
\hline Sexual & 4.5 & 5.0 & 5.8 & 6.1 & 4.5 & 5.0 \\
\hline $\begin{array}{l}\text { Drink } \\
\text { driving }\end{array}$ & 7.1 & 7.0 & 8.8 & 12.1 & 7.6 & 8.1 \\
\hline Theft & 9.4 & 9.2 & 11.8 & 9.4 & 10.6 & 10.1 \\
\hline All other & 30.5 & 33.5 & 34.8 & 31.1 & 39.0 & 34.3 \\
\hline Unknown & 20.6 & 18.3 & 13.0 & 16.4 & 10.7 & 15.6 \\
\hline Total & 100 & 100 & 100 & 100 & 100 & 100 \\
\hline Total N & 10847 & 11591 & 5966 & 6200 & 15116 & 49720 \\
\hline
\end{tabular}

Eighty seven per cent $(43,457)$ of the cases being supervised involved offenders who had one or more previous convictions or a pre-court disposal (caution, warning or reprimand). Excluding those who had only experienced a pre-court disposal meant that $84 \%$ of the total caseload could be counted as convicted recidivists. Once again, however, there were statistically significant differences between areas, with Northamptonshire's caseload containing a significantly lower proportion of previous offenders and Nottinghamshire supervising a much higher proportion. Table 8 shows that this pattern was consistent over the four quarters, reflecting the fact that the samples often contained the same people. 
Table 8: the proportion of the caseload with previous convictions by area (all time periods)

\begin{tabular}{|l|r|r|r|r|r|r|}
\hline & $\begin{array}{l}\text { Derby } \\
\text { Shire }\end{array}$ & $\begin{array}{l}\text { Leic \& } \\
\text { Rutland }\end{array}$ & \multicolumn{1}{l|}{$\begin{array}{l}\text { Lincs } \\
\%\end{array}$} & Northants & \multicolumn{1}{l|}{$\begin{array}{l}\text { Notts } \\
\%\end{array}$} & $\begin{array}{l}\text { East } \\
\text { Midlands } \\
\%\end{array}$ \\
\hline No previous & 16.3 & 16.8 & 16.2 & 19.0 & 14.4 & 16.3 \\
\hline $\begin{array}{l}\text { Previous } \\
\text { convictions }\end{array}$ & 83.7 & 83.2 & 83.8 & 81.0 & 85.6 & 83.8 \\
\hline Total N & 10847 & 11591 & 5966 & 6200 & 15116 & 49720 \\
\hline
\end{tabular}

Information was provided on length of criminal career in 41,676 cases. Of those with criminal records, less than $7 \%$ had begun offending in the last year, with half the recidivists having previous offending careers of 10 or more years. The maximum length of criminal careers appeared to range from 52 years in one area to 105 in another! Given that a small number of inaccurate entries might lead to quite misleading comparisons, differences between areas, or within areas over time, have not been presented.

\section{Conclusion}

The fact that more than four out of five cases in the 2006 local reconviction sample appeared in more than one quarter's sample is a predictable consequence of cross-sectional sampling, given that the average length of community orders nationally was 22 months by the end of 2005 (Home Office, 2006). This inevitably severely limits the degree to which changes in reconviction each quarter should be expected. Given that we know that most reconviction happens within the first year of a community sentence being imposed or post-release, the value of the results is also limited because up to a quarter of an area's community sentence cases and well over a third of their licence cases had been under supervision for over a year by the time they were sampled. Areas also varied considerably in both these respects in each snapshot and over time.

Other important differences between areas were identified in the nature of the principal offence, the proportions on licence or under a community sentence, 
the types of community sentences being supervised and the extent to which cases involved offenders with previous convictions. On this basis, it would seem unwise to use quarterly figures based on such snapshots of the supervision caseload to compare areas' reconviction rates at any given point in time or over time. As a minimum, if NOMS insist on pursuing a cross sectional approach, comparisons should be limited to sub-samples of typical cases matched on factors known to affect reconviction which had been under supervision for less than a year. However, even this would not overcome the main disadvantage of taking a cross-sectional approach, which is that it creates perverse incentives, particularly if funding is linked to improvement. Under the current approach, an area can improve its results over time by encouraging sentencers to impose longer sentences. This will not affect predicted rates but will improve actual rates. Other less obvious strategies, which it would be irresponsible to describe, could also be devised which are equally unlikely to actually make the public safer, but would lead to even greater 'improvements' in an area's reconviction rates.

The preferable, more conventional, longitudinal approach would be to produce reconviction rates based on supervision starts (commencements) each quarter with cases being followed up after six months, one year and two years. This would not in itself control for differences in demographic and criminal profile differences between offenders, but it would ensure that withinarea samples were independent and eliminate the gap between sentence or release date and the start of the follow up period. Over time the data could also be used to create genuinely local reconviction predictors rather than the current approach which is based on national figures. Although probation area is taken into account in the national predictor, the current approach may disadvantage smaller areas such as Lincolnshire and Northamptonshire whose cases will have contributed less to the cohort on which the predictor was modelled.

Adopting a longitudinal approach would ensure that local reconviction rates are less susceptible to manipulation. Examining the reconviction rates of commencements rather than caseload snapshots has a number of other 
advantages in monitoring and measuring performance. First, the six month reconviction figure would provide timely feedback on the work which is actually undertaken with those being supervised as this is the period during which National Standards requires supervision to be most intensive. In contrast, the current approach implicitly assumes that all those being supervised experience an equivalent level of intervention no matter how long they have been on the caseload. Second, by conducting six month and one year follow-ups, results would be generated concerning the period in which previous studies have shown that reconviction is most likely (the first year). Third, follow-ups of the same cases at two years would show whether short term effects were sustained. Fourth, basing reconviction rates on supervision starts would provide speedy feedback on changes in sentencing behaviour and release policies. Both of these are being masked in the current approach by the inclusion of offenders who have been under supervision for a long time. Fifth, all orders of less than three months duration would be included as a matter of course.

The open and consultative approach adopted by NOMS' reconviction analysts should ensure that the most appropriate measures of reconviction are considered, but the final decision is unlikely to lie with data analysts. In these circumstances it is worth concluding with a few cautionary words about any reconviction measure.

Reconviction rates should not be left as the sole measure of success. They are crude proxies for reoffending and a very blunt tool for measuring the desistance process. However, even if other accepted measures are developed, it is likely that reconviction rates will remain a key measure of area performance. How well they fulfil that role depends on a whole range of technical decisions about what is measured and how. To tease out the specific effect of supervision on reoffending requires allowing for who is received under supervision in different areas and over time.

NOMS' decision to depart from the standard approach to reconviction was no doubt affected by the knowledge that most consumers of local reconviction 
rates feel at least baffled, and possibly even distrustful, when anything other than simple, actual reconviction rates are discussed. The ultimate question, which is unlikely to be left to the analysts, is whether transparency or accuracy should be prioritised. The results of this further analysis demonstrate the dangers of giving too much precedence to the former and too little to the latter. 


\section{References}

Beech, A., Erikson, M, Friendship, C. and Ditchfield,J. (2001) A six-year follow-up of men going through probation-based sex offender treatment programmes, Findings 144, London: Home Office.

Blumstein, A., Cohen, J. and Farrington, D. P. (1988) 'Criminal Career research: its value for Criminology', Criminology, 28(1), 1-35.

Bottoms, A. E. (2004) 'Empirical Research Relevant to Sentencing Frameworks', in A. Bottoms, S., Rex and G. Robinson. (eds.) Alternatives to Prison: options for an insecure societ,. Cullompton: Willan Publishing.

Cann, J., Falshaw, L., Nugent, F. and Friendship, C. (2003) Understanding What Works: Accredited Cognitive Skills Programmes for Adult Men and Young Offenders, Home Office Research Findings 226, London: Home Office.

Carter, P (2003) Managing Offenders, Changing Lives: a new approach, London: Home Office.

Cunliffe, J. and Shepherd, A. (2007) Re-offending of adults: results from the 2004 cohort, Home Office Statistical Bulletin 06/07, London: Home Office.

Cuppleditch, L. and Evans, W. (2005) Re-offending of adults: results from the 2002 cohort. Home Office Statistical Bulletin 25/05, London: Home Office.

Farrall, S. (2002) Rethinking What Works with Offenders: Probation, Social Context and Desistance from Crime, Cullompton: Willan.

Farral, S. (2005) 'Officially recorded convictions for probationers: The relationship with self-report and supervisory observations', Legal and Criminal Psytchology, 10 (1), 121-131.

Farrington, D.P., Coid, J.W., Harnett, L., Jolliffe, D., Soteriou, N., Turner, R. and West, D.J. (2006) Criminal Careers up to age 50 and Life Success up to age 48: New Findings from the Cambridge Study in Delinquent Development, Home Office Research Study 299, London: Home Office.

Friendship, C., Mann, R. and Beech, A. (2003) The prison-based Sex Offender Programme - an evaluation, Findings 205, London: Home Office.

Friendship, C., Street, R., Cann, J. and Harper, G. (2004) 'Introduction: the policy context and assessing the evidence' in G. Harper and C. Chitty (eds.), The impact of corrections on re-offending: a review of 'what works', Home Office Research Study 291, London: Home Office. 
Hedderman C. (2006) 'Keeping the lid on the prison population: will it work?', in M. Hough, R. Allen and U. Padel (eds.) Reshaping probation and prisons: The new offender management framework (2006), London: Polity Press.

Hedderman, C. (2007) 'Past, present and future sentences: what do we know about their effectiveness?' in (eds.) L.R. Gelsthorpe and R. Morgan The Probation Handbook. Cullompton, Devon: Willan.

Hedderman, C. (2008) 'Building on sand: why expanding the prison estate is not the way to secure the future' in M. Hough, R. Allen and E. Solomon (eds) Tackling Prison Overcrowding. Bristol: Policy Press.

Home Office (1993) Reconvictions of those given Probation and Community service orders in 1987, Statistical Bulletin 18/93, London: Home Office.

Home Office (2004) Reducing Reoffending: National Action Plan, London: Home Office.

Home Office (2006) Offender Management Caseload Statistics 2005 England and Wales, Home Office Statistical Bulletin 18/06, London: Home Office.

Kershaw, C. and Renshaw, G. (1997a) Reconvictions of prisoners discharged from prison in 1993, England and Wales, Statistical Bulletin 5/97, London: Home Office.

Kershaw, C. and Renshaw, G. (1997b) Reconvictions of those commencing community penalties in 1993, England and Wales, Statistical Bulletin 6/97, London: Home Office.

Killias, M., Aebi, M. and Ribeaud, D. (2000) 'Does Community Service Rehabilitate better than Short-term Imprisonment? Results of a Controlled Experiment', The Howard Journal, 39(1), pp. 40-57.

Loeber, R., \& Stouthamer-Loeber, M. (1998). 'The development of juvenile aggression and violence: Some common misconceptions and controversies', American Psychologist, 53, 242-259.

Lloyd, C., Mair, G. and Hough, M. (1994) Explaining Reconviction Rates: a Critical Analysis, Home Office Research Study 136, London:HMSO.

Mair, G., Lloyd, C., and Hough, M (1997) 'The limitations of reconviction rates' in G. Mair (ed.) Evaluating the Effectiveness of Community Penalties, Aldershot: Avebury.

McNeill, F. (2006) 'A Desistance Paradigm for Offender Management', Criminology and Criminal Justice: An International Journal 6 (1): 39-62.

Merrington, S.and Stanley, S. (2004) 'What Works?': Revisiting the Evidence in England and Wales, Probation Journal, 51(1): 7-20. 
Merrington, S.and Stanley, S. (2007) 'Effectiveness: Who counts What?' in L.R. Gelsthorpe and R. Morgan. (eds.) The Probation Handbook. Collumpton, Devon: Willan.

Ministry of Justice (2008) Re-offending of adults: new measures of reoffending 2000-2005 England and Wales, Statistics bulletin, London: Ministry of Justice.

Moxon, D (1998) 'The role of sentencing policy' in P. Goldblatt and C. Lewis (eds.) Reducing reoffending: an assessment of research evidence on ways of dealing with offending behaviour, Home Office Research Study 187, London: Home Office.

Nagin, D.S., (1998) 'Deterrence and incapacitation' in M. Tonry, (ed.) The Handbook of Crime and Punishment, New York: Oxford University Press.

Oldfield, M. (1997) 'What worked? A five year study of probation reconvictions', Probation Journal, 44 (1) 2-10.

Sarno, C, Hearnden, I. and Hedderman, C. (2001) From Offending to Employment: a study of two probation schemes in Inner London and Surrey, Home Office Research Findings No 135, London: Home Office: Research and Statistics Directorate.

Spicer, K. and Glicksman, A. (2004) Adult Reconviction: results from the 2001 cohort, On-line report 59/04, London: Home Office.

United Kingdom Longitudinal Research Centre (2008) Why Longitudinal Research? http://www.iser.essex.ac.uk/ulsc/about/whylong.php

von Hirsch, A., Bottoms, A., Burney E. and Wikström, P-O.(1999) Criminal deterrence and sentence severity: an analysis of recent research, Oxford: Hart Publishing. 